\title{
Age-related differences in flexibility in soccer players 8-19 years old
}

\author{
Antonio Cejudo ${ }^{1}$, Francisco Javier Robles-Palazón ${ }^{1}$, Francisco Ayala ${ }^{2}$, Mark De Ste Croix ${ }^{3}$, Enrique Ortega- \\ Toro $^{1}$, Fernando Santonja-Medina ${ }^{4}$, Pilar Sainz de Baranda ${ }^{\text {Corresp. } 1}$ \\ 1 Department Physical Activity and Sport / Faculty of Sport Sciences / Campus of Excellence Mare Nostrum, Universidad de Murcia, Murcia, Spain \\ 2 Sports Research Centre, Miguel Hernández University of Elche, Alicante, Spain \\ 3 School of Sport and Exercise, University of Gloucestershire, Gloucester, United Kingdom \\ ${ }^{4}$ Virgen de la Arrixaca University Hospital / Faculty of Medicine / Campus of Excellence Mare Nostrum, Universidad de Murcia, Murcia, Spain \\ Corresponding Author: Pilar Sainz de Baranda \\ Email address: psainzdebaranda@um.es
}

Background: Muscle flexibility is a main component of health-related fitness and one of the basic components of fitness for the performance in some sports. Sport and health professionals require the flexibility profile of soccer to define quantitative aims in the training of flexibility. The aim of this study was to identify age-related differences in lower extremity flexibility in youth soccer players. Methods: Seventy-two young male soccer players (age: $13.0 \pm 3.1$ y; body mass: $50.5 \pm 15.3 \mathrm{~kg}$; stature $158.2 \pm 16.8 \mathrm{~cm}$; BMl: $19.6 \pm 2.6 \mathrm{~kg} / \mathrm{m}^{2}$ ) completed this study. Measures of eleven passive hip (hip extension [HE], hip adduction with hip flexed 90 [HAD-HF90], hip flexion with knee flexed [HF-KF] and extended [HF-KE], hip abduction with hip neutral [HAB] and hip flexed 90 [HAB-HF90], hip external [HER] and internal [HIR] rotation), knee (knee flexion [KF]) and ankle dorsiflexion (ankle dorsiflexion with knee flexed [ADF-KF] and extended [ADF-KE]) ranges of motion (ROM) were taken. Descriptive statistics were calculated for hip, knee and ankle ROM measured separately by leg (dominant and non-dominant) and age-group (U10, U12, U14, U16 and U19). The data was analysed using a one-way analysis of variance (ANOVA) to examine the interaction of 11 ROM in the different players' age-group. Results: Generally, U10 and/or U12 soccer players obtain the highest mean value in almost all ROM

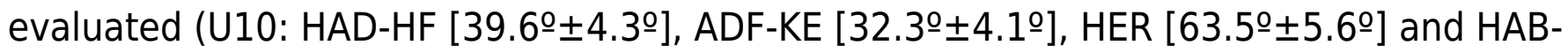

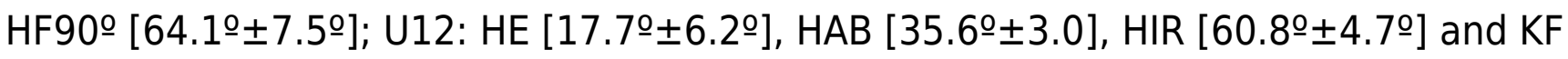
$\left.\left[133.8^{\circ} \pm 7.10\right]\right)$. Nonetheless, significant differences between the players' age-groups are just found in HAD-HF90o $(p=.042 ; \mathrm{ES}=.136), \operatorname{HAB}(p=.001 ; \mathrm{ES}=.252), \operatorname{HIR}(p=.001$; $\mathrm{ES}=.251)$, HER $(p<.001 ; \mathrm{ES}=.321)$ and HAB-HF90o $(p<.001 ; \mathrm{ES}=.376)$ ROM, showing a progressive and irregular decrease in these ROM until the U19 team. Conclusion: The findings of this study reinforce the necessity of prescribing exercises aimed at improving HAD-HF90 ROM in U16, HAB ROM in U14, HIR ROM in U16 and U19, HER ROM in U12 and 
U19, and HAB-HF90 ROM in U16 and U19 players within everyday soccer training routines. 


\section{AGE-RELATED DIFFERENCES IN FLEXIBILITY IN}

2 SOCCER PLAYERS 8-19 YEARS OLD

3

4

5
6

Antonio Cejudo ${ }^{1}$, Francisco Javier Robles-Palazón ${ }^{1}$, Francisco Ayala ${ }^{2}$, Mark De Ste Croix ${ }^{3}$, Enrique Ortega-Toro ${ }^{1}$, Fernando Santonja-Medina ${ }^{4}$, Pilar Sainz de Baranda ${ }^{1}$.

${ }^{1}$ Department of Physical Activity and Sport, Faculty of Sport Sciences, Campus of Excellence Mare Nostrum, University of Murcia, Murcia, Spain

${ }^{2}$ Sports Research Centre, Miguel Hernández University of Elche, Alicante, Spain.

${ }^{3}$ School of Sport and Exercise, University of Gloucestershire, Gloucester, United Kingdom. ${ }^{4}$ Virgen de la Arrixaca University Hospital. Faculty of Medicine. Campus of Excellence Mare Nostrum. University of Murcia, Spain.

Corresponding Author:

Pilar Sainz de Baranda ${ }^{1}$

C/Argentina s/n, 30720. Santiago de la Ribera-San Javier, Murcia (Spain).

Email address: psainzdebaranda@um.es

\section{ABSTRACT}

Background: Muscle flexibility is a main component of health-related fitness and one of the basic components of fitness for the performance in some sports. Sport and health professionals require the flexibility profile of soccer to define quantitative aims in the training of flexibility. The aim of this study was to identify age-related differences in lower extremity flexibility in youth soccer players.

Methods: Seventy-two young male soccer players (age: $13.0 \pm 3.1 \mathrm{y}$; body mass: $50.5 \pm 15.3 \mathrm{~kg}$; stature $158.2 \pm 16.8 \mathrm{~cm}$; BMI: $19.6 \pm 2.6 \mathrm{~kg} / \mathrm{m}^{2}$ ) completed this study. Measures of eleven passive hip (hip extension [HE], hip adduction with hip flexed $90^{\circ}$ [HAD-HF90 ${ }^{\circ}$, hip flexion with knee flexed [HF-KF] and extended [HF-KE], hip abduction with hip neutral [HAB] and hip flexed $90^{\circ}$ [HAB-HF90 $0^{\circ}$, hip external [HER] and internal [HIR] rotation), knee (knee flexion [KF]) and ankle dorsiflexion (ankle dorsiflexion with knee flexed [ADF-KF] and extended [ADF-KE]) ranges of motion (ROM) were taken. Descriptive statistics were calculated for hip, knee and ankle ROM measured separately by leg (dominant and non-dominant) and age-group (U10, U12, U14, U16 and U19). The data was analysed using a one-way analysis of variance (ANOVA) to examine the interaction of 11 ROM in the different players' age-group.

Results: Generally, U10 and/or U12 soccer players obtain the highest mean value in almost all ROM evaluated (U10: HAD-HF $\left[39.6^{\circ} \pm 4.3^{\circ}\right]$, ADF-KE $\left[32.3^{\circ} \pm 4.1^{\circ}\right]$, HER $\left[63.5^{\circ} \pm 5.6^{\circ}\right]$ and HAB-HF90 $0^{\circ}\left[64.1^{\circ} \pm 7.5^{\circ}\right]$; U12: HE $\left[17.7^{\circ} \pm 6.2^{\circ}\right], \operatorname{HAB}\left[35.6^{\circ} \pm 3.0\right], \operatorname{HIR}\left[60.8^{\circ} \pm 4.7^{\circ}\right]$ and KF $\left.\left[133.8^{\circ} \pm 7.1^{\circ}\right]\right)$. Nonetheless, significant differences between the players' age-groups are just found in $\operatorname{HAD}-\mathrm{HF}_{0} 0^{\circ}(p=.042 ; \mathrm{ES}=.136), \mathrm{HAB}(p=.001 ; \mathrm{ES}=.252), \operatorname{HIR}(p=.001 ; \mathrm{ES}=$ 
40

41

42

43

44

45

46

47

48

49

50

51

52

53

54

55

56

57

58

59

60

61

62

63

64

65

66

67

68

69

70

71

72

73

74

75

76

77

78

79

$.251), \operatorname{HER}(p<.001 ; \mathrm{ES}=.321)$ and HAB-HF90 $(p<.001 ; \mathrm{ES}=.376)$ ROM, showing a progressive and irregular decrease in these ROM until the U19 team.

Conclusion: The findings of this study reinforce the necessity of prescribing exercises aimed at improving HAD-HF90 ROM in U16, HAB ROM in U14, HIR ROM in U16 and U19, HER ROM in U12 and U19, and HAB-HF90 ROM in U16 and U19 players within everyday soccer training routines.

\section{INTRODUCTION}

Soccer is by far the world's most popular sport (Dvorak, Junge, \& Graf-Baumann, 2004).

According to the survey conducted by the International Federation of Association Football (FIFA) in 2006, more than 270 million participants played soccer in the world and most of them were male players ( $90 \%$ of all registered players), with younger soccer players comprising the greatest proportion (54.7\%) (FIFA, 2006).

Soccer requires players to perform many repeated high intensity movements such as sudden acceleration and deceleration, lots of changes of direction, jumping and landing tasks, as well as many situations in which players are involved in tackling to keep or obtain possession of the ball (Krustrup et al., 2010). Optimal performance in these actions depends upon a variety of anthropometrical and physiological properties (Arnason et al., 2004; Pion, et al. 2015; Stolen, Chamari, Castagna, \& Wisloff, 2005). For example, body composition has been identified as an important factor which could adjust the performance in soccer players across the season due to the contribution that body fat and lean muscle mass have on some physical abilities (Carling \& Orhant, 2010; Milanese, Cavedon, Corradini, De Vita, \& Zancanaro, 2015). Likewise, some authors identified endurance, repeated-sprint ability, velocity, agility and strength as the main properties and optimal performance factors in this sport (Haugen, Tonnessen, \& Seiler, 2013; Rebelo, Brito, Seabra, Oliveira, \& Krustrup, 2014; Stolen, et al., 2005; Wong, Hjelde, Cheng, \& Ngo, 2015). Nevertheless, it seems anthropometrical and physiological demands are specific for each soccer player and depend on the participants' sex, position and age (Di Salvo et al., 2007; Le Gall, Carling, Williams, \& Reilly, 2010; Oyón, Franco, Rubio, \& Valero, 2016; Wong, Chamari, Dellal, \& Wisloff, 2009).

Muscle flexibility is a main component of health-related fitness, and one of the basic components of the performance in some sports (Kraemer \& Gómez, 2001); in soccer, deficits in some ranges of motion might restrict specific technical skills and reduce players' performance (GarcíaPinillos, Ruiz-Ariza, Moreno del Castillo, \& Latorre-Román, 2015; Mills et al., 2015; Nunome, Ikegami, Kozakai, Apriantono, \& Sano, 2006). Although there is no consistent scientific evidence about the relationship between flexibility and injury risk, it seems lower range of motion values in soccer players could also increase the risk of some muscle injuries (Bradley \& Portas, 2007; Henderson, Barnes, \& Portas, 2010; Witvrouw, Danneels, Asselman, D’Have, \& Cambier, 2003). In sport, it has been observed that flexibility is subject to sex (Gómez-Landero, López, \& Vernetta, 2013; Kibler \& Chandler, 2003), tactical position (Oberg, Ekstrand, Möller, \& Gillquist, 1984; Sporis, Vucetic, Jovanovic, Jukic, \& Omrcen, 2010), dominant laterality (Bittencourt et al., 2014; Rahnama, Lees, \& Bambaecichi, 2005) and competitive level (Rubini, 
80 Costa, \& Gomes, 2007). However, there are few articles where muscle flexibility was directly 81 related to the age of soccer players (Malina, Ribeiro, Aroso, \& Cumming, 2007; Manning \& 82 Hudson, 2009; Nikolaïdis, 2012; Vaeyens et al., 2006). A general trend towards the flexibility 83 reduction over ages has been reported by previous studies conducted in non-athlete population 84 (McKay et al., 2017). The knowledge of flexibility changes in relation to the age of soccer 85 players could show the variation of this capability throughout the different phases of sport 86 specialization, providing useful information about the critical flexibility stages and the primary 87 affected muscles to physical trainers. Therefore, the aim of this study is to identify age-related 88 differences in lower extremity flexibility in young soccer players.

89

90

91

92

93

\section{MATERIALS \& METHODS}

\section{Participants}

Seventy-two young soccer players completed this study. The participants were recruited from five different teams $(\mathrm{U} 10=16$ players; $\mathrm{U} 12=15$ players; $\mathrm{U} 14=13$ players; $\mathrm{U} 16=15$ players; $\mathrm{U} 19=13$ players) of a youth soccer academy (Table 1). All the participants were outfield players and participated regularly in sport (3-4 training sessions and 1 match per week). Also, none of the participants were involved in systematic and specific stretching regimes in the last 6 months, apart from the 1-2 sets of 8-10 s of static stretches designated for the major muscles of the lower extremities (e.g. hamstrings, quadriceps, adductors and triceps surae) that were performed daily during their pre-exercise warm-up and post-exercise cool down phases.

The exclusion criterion was history of orthopaedic problems to the knee, thigh, hip, or lower back in the last 3 months due to the fact that residual symptoms could have an impact in the habitual players' movement competency and/or lower extremity ROM profile. The study was conducted at the end of the preseason phase of the year 2016. The time frame of the study was selected to make sure that the players recruited to each team were definitive and stable within the testing period.

Before any participation, experimental procedures and potential risks were fully explained to both parents and children in verbal and written form, and written informed consent was obtained. The experimental procedures used in this study were in accordance with the Declaration of Helsinki and were approved by the Ethics and Scientific Committee of the University of Murcia (Spain) (ID: 1551/2017).

\section{Testing procedure}

The passive hip extension [HE], hip adduction with hip flexed $90^{\circ}$ [HAD-HF90 $]$, hip flexion with knee flexed [HF-KF] and extended [HF-KE], hip abduction with hip neutral [HAB] and hip flexed $90^{\circ}$ [HAB-HF90 ${ }^{\circ}$, hip external [HER] and internal [HIR] rotation, knee flexion [KF], ankle dorsiflexion with knee flexed [ADF-KF] and extended [ADF-KE] ROM of the dominant and non-dominant leg were assessed following the methodology previously described (Cejudo, Sainz de Baranda, Ayala, \& Santonja, 2014a) (Figure 1).

119 Organizations, American Academy of Orthopaedic Surgeons [AAOS] (1965) and American 
120 Medical Association (Gerhardt, Cocchiarella, \& Lea, 2002) and included in manuals of sports

121

122

123

124

125

126

127

128

129

130

131

132

133

134

135

136

137

138

139

140

141

142

143

144

145

146

147

148

149

150

151

152

153

154

155

156

157

158

159

medicine and science (Magee, 2002; Palmer \& Epler, 2002) based on reliability and validity studies, anatomical knowledge, and extensive clinical and sport experience (Cejudo, Ayala, Sainz de Baranda, \& Santonja, 2015 a,b; Cejudo, Sainz de Baranda, Ayala, \& Santonja, 2014b). In addition, the intra-operator variability was analysed for each muscle flexibility measure using a test-retest design. Before data collection, the reliability coefficient was evaluated on 20 healthy athletes. The range of motion was measured twice with a 2-week interval. An interclass correlation coefficient (ICC) and the minimal detectable change at $95 \%$ confidence interval $\left(\mathrm{MDC}_{95}\right)$ were calculated from the results of subsequent measurements. Results of pre-and-postmeasurements showed a high reliability coefficient in all the tests (HF-KF [0.94], HF-KE [0.97], HE [0.97], HAD-HF [0.97], HAB [0.95], HAB-HF90 [0.96], HER [0.96], HIR [0.96], KF [0.95], ADF-KE [0.95], and ADF-KF [0.95]). The $\mathrm{MDC}_{95}$ for each flexibility measure ranged from $3.7^{\circ}$ to $6.9^{\circ}$ (HF-KF $\left[6.2^{\circ}\right.$, HF-KE [6.1 $]$, HE [3. $\left.7^{\circ}\right]$, HAD-HF [5 $\left.5^{\circ}\right]$, HAB [5.5 $]$, HABHF90 ${ }^{\circ}\left[4.7^{\circ}\right]$, HER $\left[4.7^{\circ}\right]$, HIR $\left[4.1^{\circ}\right], \operatorname{KF}\left[6.9^{\circ}\right]$, ADF-KE $\left[4.7^{\circ}\right]$, and ADF-KF [5 $\left.\left.5^{\circ}\right]\right)$.

One week before the start of the study, all the soccer players completed a familiarization session with the purpose of getting to know the correct technical execution of the exploratory tests by means of the practical realization of each one of them. The dominant leg was defined as the participant's preferred kicking leg. All tests were carried out by the same two sport scientists (one conducted the tests and the other ensured proper testing position of the participants throughout the assessment manoeuvre) under stable environmental conditions. The sport scientists were blinded to the purpose of the study and to the test results from previous testing sessions.

Prior to the testing session, all participants performed the dynamic warm-up designed by Taylor, Sheppard, Lee, \& Plummer (2009). The overall duration of the entire warm-up was approximately $20 \mathrm{~min}$. A 3-5 min rest interval between the end of the warm-up and beginning of the ROM assessment was given to the soccer players because in a pilot study with 10 participants of similar age and training status, sometime was required for practical reasons, like rehydrating and drying their sweat prior to the ROM assessment. More importantly, it has been shown that the effects elicited by the dynamic warm-up on muscle properties might last more than 5 min (Ayala, Moreno-Pérez, Vera-Garcia, Moya, Sanz-Rivas, \& Fernandez-Fernandez, 2016) and hence, decreases in ROM values within the 3-5 min rest interval were not expected.

After the warm-up, soccer players were instructed to perform, in a randomised order, two maximal trials of each ROM test for each leg, and the mean score for each test was used in the analysis. Soccer players were examined wearing sports clothes and without shoes. A 30s rest was given between trials, legs and tests.

For the measurement, an ISOMED Unilevel inclinometer (Portland, Oregon) was used with an extendable telescopic rod (Gerhardt, Cocchiarella, Lea, 2002), a metal goniometer with long arm (Baseline ${ }^{\circledR}$ Stainless) and "lumbosant" -lumbar support- to standardize the lumbar curvature (Santonja, Ferrer, \& Martínez, 1995; Sainz de Baranda, Rodríguez-Iniesta, Ayala, Santonja, \& Cejudo, 2014). 
160 Before each assessment session, the inclinometer was calibrated to $0^{\circ}$ with either the vertical or

161

162

163

164

165

166

167

168

169

170

171

172

173

174

175

176

177

178

179

180

181

182

183

184

185

186

187

188

189

190

191

192

193

194

195

196

197

198

199

horizontal axis. The angle between the longitudinal axis of the mobilized segment was recorded (following its bisector) with the vertical or the horizontal (Cejudo et al, 2014a; Gerhardt et al., 2002). Regarding the assessment of hip abduction movement, a metal goniometer of long arm (Baseline ${ }^{\circledR}$ Stainless) was used.

One or both of the following criteria determined the endpoint for each test: (a) an examiner palpable or appreciated some compensation movement that increased the ROM onset of pelvic rotation, and/or (b) the soccer player feeling a strong but tolerable stretch, slightly before the occurrence of pain (Cejudo et al., 2014b).

\section{Statistical analysis}

Prior to the statistical analysis, the distribution of raw data sets was checked using the Kolmogorov-Smirnov test and demonstrated that all data had a normal distribution $(p>.05)$.

Descriptive statistics including means and standard deviations were calculated for hip, knee and ankle ROM measurements, separately by leg (dominant and non-dominant). Dependent sample ttests were carried out to assess differences between the values of the dominant and non-dominant sides. Also, data was analysed using a one-way analysis of variance (ANOVA) to examine the interaction of 11 ROM at different youth teams. Post hoc comparisons were made using the Bonferroni test for pair wise comparisons. Analysis was completed using SPSS version 20 (SPSS Inc, Chicago, IL, USA). The effect sizes (ES) of each variable were tested using eta squared ( $\eta 2$ ) between groups $(.01=$ small effect, $.06=$ medium effect, and $.14=$ large effect [Cohen, 1988]). Statistical significance was set at $p<.05$.

\section{RESULTS}

Statistical analysis reported no differences between dominant and non-dominant sides for each ROM value, so the mean scores were used for comparing age-groups. Table 2 shows the results of the 11 ROM variables of the ROM-SPORT protocol in soccer players, differentiating the data between the 5 youth teams. Generally, U10 and/or U12 soccer players obtained the highest mean value in almost all ROM evaluated (HE, HAD-HF, ADF-KE, HAB, HIR, HER, HAB-HF90 ${ }^{\circ}$ and $\mathrm{KF}$ ). Nonetheless, significant differences between the players' age-group (large effect) are only found in $\operatorname{HAD}-H F 90^{\circ}\left(\mathrm{F}_{4,67}=2.629 ; p=.042 ; \mathrm{ES}=.136\right), \mathrm{HAB}\left(\mathrm{F}_{4,67}=5.642 ; p=.001 ; \mathrm{ES}=\right.$ $.252), \operatorname{HIR}\left(\mathrm{F}_{4,67}=5.624 ; p=.001 ; \mathrm{ES}=0.251\right), \operatorname{HER}\left(\mathrm{F}_{4,67}=7.930 ; p<.001 ; \mathrm{ES}=.321\right)$ and HAB-HF $90^{\circ}\left(\mathrm{F}_{4,67}=10.074 ; p<.001 ; \mathrm{ES}=.376\right) \mathrm{ROM}$, showing a progressive and irregular decrease in these ROM until the U19 team. On the contrary, the greatest mean value in the HF$\mathrm{KE}\left(\mathrm{F}_{4,67}=.847 ; p=.501 ; \mathrm{ES}=.048\right)$ and $\mathrm{HF}-\mathrm{KF}\left(\mathrm{F}_{4,67}=1.674 ; p=.166 ; \mathrm{ES}=.091\right) \mathrm{ROM}$ is observed in U19 players, but these differences are not statistically significant. U10 players report the highest values in HAD-HF90 ${ }^{\circ}$, HER and HAB-HF90 ${ }^{\circ} \mathrm{ROM}$. The Bonferroni post hoc comparisons reflect statistical differences with U16 players $(p=.035)$ in HAD-HF90, $\mathrm{U} 12(p<.001)$ and U19 $(p=.001)$ players in HER, and U14 $(p=.003)$, U16 ( $p<$ $.001)$ and $\mathrm{U} 19(p<.001)$ players in HAB-HF90 ${ }^{\circ}$. U12 players obtained the highest ROM in HAB and HIR; the Bonferroni post hoc comparisons showed statistical differences with U14 ( $p$ 
$200=.001)$ and U16 $(p=.04)$ in HAB, and U16 $(p=.001)$ and U19 $(p=.003)$ in HIR. The

201 Bonferroni post hoc test also indicated significant differences between U12 players and U14 ( $p=$ $202.019)$, U16 ( $p=.002)$ and U19 ( $p=.001)$ soccer players in HAB-HF90 ROM. Finally, the

203 Bonferroni post hoc test showed significant differences in U14 vs. U10 ( $p=.011)$ and U14 vs.

$204 \mathrm{U} 19(p=.021)$ in HAB, and U16 vs. U12 $(p=.005)$ and U16 vs. U19 $(p=0.01)$ soccer players

205 in HER (Figure 2).

206

\section{DISCUSSION}

208 The purpose of the current study was to identify age-related differences in lower extremity

209 flexibility in young soccer players. The principal results of this research indicated that the U10

210 and U12 soccer players had the highest values in several (HE, HAD-HF, ADF-KE, HAB, HIR,

211 HER, HAB-HF90 and KF), but not all (HF-KE and HF-KF) of the ROM assessed in

212 comparison with their counterpart older players.

213 Flexibility seems to decline with age (Medeiros, Araújo, \& Araújo, 2013). Johns \& Wright

214 (1962) determined that the relative contributions of soft tissue to total resistance encountered at a

215 joint are as follows: joint capsules, 47\%; muscle and its fascia, 41\%; tendons and ligaments,

$21610 \%$; and skin, 2\%. Evidence suggests that biological changes such as tendon stiffening, joint

217 capsule changes, or muscle changes could be responsible factors for the age-related decrease in

218 flexibility (Adams, O'Shea, \& O'Shea, 1999). In this sense, our data supports this statement

219 showing a slight tendency to reduce the ROM during different periods of soccer practice

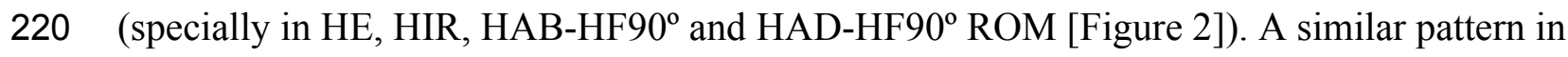

221 some of the hip ROM over the development phases was previously reported by Manning \&

222 Hudson (2009) who also found significant lower ROM values in HE, HIR, HAB-HF90 in senior

223 soccer players compared to their equals' young players. The poor flexibility showed by older

224 players in these ROM may also reflect an adaptive response to playing soccer of soft tissue

225 around the joints that improves stability at the specific joint, or lack of attention to flexibility

226 practices in training (Ostojić \& Stojanović, 2007). Thus, training and repetition of specific soccer

227 skills like kicking the ball might explain the reduction of scores in HIR, HE and HAB-HF90

228 tests throughout the different age-groups as a result of adaptation to this continuous contraction

229 of external hip rotator, hip flexor and hip adductor muscles. Indeed, these kicking adaptations

230 would be in agreement with the lower values found by López-Valenciano et al. (2018) in his

231 recent study in professional soccer players in HE $\left(8.9^{\circ}\right)$ and HIR (47.1 $)$ ROM. Taking into

232 account that these reductions could predispose players to abnormal movement patterns and

233 increase the degeneration or capsular tightening in the hip joint (Manning \& Hudson, 2009), it is

234 essential to perform stretching exercises aiming to improve the hip ROM.

235 On the contrary, older players have shown better values of ROM in KH-KF and, mainly, in HF-

236 KE. The HF-KE test assesses the flexibility of hamstring muscles. Some previous studies have

237 also shown similar increases in older soccer players' hamstring flexibility in comparison with

238 their younger counterparts using the sit-and-reach test (Nikolaïdis, 2012; Vaeyens et al., 2006).

239 During the early childhood and adolescence ages the growth of bone and muscle play important 
240 roles in force development, musculoskeletal loading and motor control during childhood.

241 Differential bone growth (femur) in relation to muscle length can result in a decrease in 242 flexibility (hamstring) and strength (De Ste Croix \& Korff, 2012). In addition, these muscles

243 have been the most studied muscle group by scientific literature, given that they represent one of 244 the most injured areas in sport, in general, and soccer, in particular (Nogueira, Laiginhas, Ramos, 245 \& Costa, 2017; Price, Hawkins, Hulse, \& Hodson, 2004). Several published injury prevention programs include hamstring dynamic or static stretching exercises in order to increase the flexibility in these muscles (DiStefano, Padua, DiStefano, \& Marshall, 2009; Kiani et al., 2010). Perhaps, the great incidence rates of hamstring injuries could explain an increase in the use of flexibility training as a hamstring injury prevention strategy by the practitioners, allowing better scores in HF-KE test in more trained athletes. Likewise, repetitive soccer skills as kicking the ball where a hip flexion is performed accompanied by a knee almost full extended could be a feasible reason to explain why older players present higher values in HF-KE ROM. These adaptations in HF-KE ROM will be again in agreement with the results shown by LópezValenciano et al. (2018) in professional soccer players (80.3 $3^{\circ} \mathrm{HF}-\mathrm{KE}$ ROM). Appropriate body status requires a minimum of flexibility to respond to the demands of sport practise. Although there is no strong scientific evidence, flexibility appears to be also necessary for sport performance in youth. In U16 soccer players, greater flexibility of the lower back and upper thigh might discriminate players with high skill levels (Vaeyens et al., 2006); in young soccer players with an age range from 14 to 18 year olds, hamstring flexibility was established as a key factor for performing football-specific skills, such as sprinting, jumping, agility, and kicking (García-Pinillos, Ruiz-Ariza, Moreno del Castillo, \& Latorre-Román, 2015). The efficacy of the traditional stretching techniques (such as static, dynamic, PNF or ballistic) in the improvement of ROM results have been reported in several studies (Ayala, Sainz de Baranda, \& Cejudo, 2012; Ayala, Sainz de Baranda, \& De Ste Croix, 2012; Ayala, Sainz de Baranda, De Ste Croix, \& Santonja, 2013; Sainz de Baranda \& Ayala, 2010); by the same token, new protocols as the combination of traditional techniques with electrical stimulation (Piqueras-Rodríguez, Palazón-Bru, \& Gil-Guillén, 2016) have shown important enhancements in the flexibility of soccer players with reduced ROM. Therefore, the inclusion of sport-specific flexibility work in training routines could help to increase the ROM values and to improve sport performance. The appropriate stretching protocols and work-loads have to be selected by the practitioners to increase flexibility and to maintain it throughout the distinct stages of youth physical development, following the recommendations proposed by Lloyd \& Oliver (2012). Specially, these exercises should be aimed at young players with limited ROM; so it is essential to evaluate athletes' flexibility profile. On this matter, new predictive mobile apps have been published to determine boy soccer players with a higher muscle (hamstring) ROM restriction which can be used to make a simple and quickly assessment of our soccer teams (Piqueras-Rodríguez,

278 However, it is unclear what level of flexibility is optimum to improve performance and to 279 prevent injuries in soccer. Optimal values may vary between muscle groups and different sports 
280 (Ostojić \& Stojanović, 2007; Sainz de Baranda, Cejudo, Ayala, \& Santonja, 2015); while a 281 swimmer needs higher values in the shoulder and ankle ROM, a dancer requires huge values in 282 almost all (upper and lower extremity) ROM. Even within the same sport, the optimal values 283 depend on the demands of the players' position and age; the goalkeeper will need distinct upper 284 extremity ROM than the field player, and the differences in the movement patterns developed by 285 children and adolescents will possibly require diverse degrees of ROM (as it happens with knee 286 angular velocity in kicking [Kellis \& Katis, 2007]). The current study intends to analyse the 287 flexibility differences between young soccer players in relation to their chronological age. Due to 288 the lack of flexibility normative values in youth soccer, the flexibility profile derived from our 289 results could be used as minimum objective scores to achieve in each age-group. Nonetheless, 290 and having into account that soccer success is based on many different variables (Nikolaïdis, Ziv, 291 Lidor, \& Arnon, 2014), it is necessary to publish prospective cohort studies adopting holistic 292 approaches for predicting the exact cut off score in each physical skill that implies a higher sport 293 performance and lower injury risk.

294 One of the principal limitations of this research was the sample size used in each group (U10, 295 U12, U14, U16 and U19); the limited number of players in each of the youth academy teams 296 hinders the athletes' involvement. Other limitation could be that neither index of maturity nor 297 player position was assessed within the study. Future studies should analyse possible differences 298 in flexibility in regard to players' maturational status and tactical position.

299

300

301

302

303

CONCLUSIONS

U10 and U12 soccer players display highest values in five of the ROM assessed (HAD-HF90', $\mathrm{HAB}, \mathrm{HIR}, \mathrm{HER}, \mathrm{HAB}-\mathrm{HF} 90^{\circ}$ ). On the contrary, older players (U19) showed better ROM in HF-KE and HF-KF tests in comparison with their younger peers. The ROM reductions in internal and external hip rotation and hip adduction and abduction movements throughout the studied ages could explain an adaptive response of the muscles involved in playing soccer. The

306

307

308

309

310 ROM restriction could predispose players to abnormal movement patterns and increase the risk of future injuries in the joints involved. Thus, the findings of this study reinforce the necessity of prescribing exercises aimed at improving HAD-HF90 ROM in U16, HAB ROM in U14, HIR ROM in U16 and U19, HER ROM in U12 and U19, and HAB-HF90 ROM in U16 and U19 players within everyday soccer training routines. 


\section{REFERENCES}

312 Adams, K., O'shea, P., \& O'shea, K. L. (1999). Aging: its effects on strength, power, flexibility, 313 and bone density. Strength \& Conditioning Journal, 21(2), 65-77.

314 American Academy of Orthopedic Association (1965). Joint Motion: Method of Measuring and 315 Recording. Chicago: Park Ridge.

316 Arnason, A., Sigurdsson, S. B., Gudmundsson, A., Holme, I., Engebretsen, L., \& Bahr, R.

317 (2004). Risk factors for injuries in football. The American Journal of Sports Medicine, 32(1

318 suppl), 5S-16S.

319 Ayala, F., Moreno-Pérez, V., Vera-García, F. J., Moya, M., Sanz-Rivas, D., Fernández-

320 Fernández, J. (2016). Acute and time-course effects of traditional and dynamic warm-up routines 321 in young elite junior tennis players. PloS one, 11(4), e 0152790.

322 Ayala, F., Sainz de Baranda, P., \& Cejudo, A. (2012). El entrenamiento de la flexibilidad:

323 técnicas de estiramiento. Revista Andaluza de Medicina del Deporte, 5(3), 105-112.

324 Ayala, F., Sainz de Baranda, P., \& De Ste Croix, M. (2012). Estiramientos en el calentamiento:

325 diseño de rutinas e impacto sobre el rendimiento. Revista Internacional de Medicina y Ciencias 326 de la Actividad Física y del Deporte, 12(46), 349-368.

327 Ayala, F., Sainz de Baranda, P., De Ste Croix, M., \& Santonja, F. (2013). Comparison of active 328 stretching technique in males with normal and limited hamstring flexibility. Physical Therapy in 329 Sport, 14(2), 98-104.

330 Bittencourt, N., Ocarino, J., Sorrentino, F., Jales, F., Gabriel, S., \& Mendonça, L. (2014).

331 Normative data for muscle flexibility in male soccer players. British Journal of Sports Medicine, 332 48(7), 560-674.

333 Bradley, P., \& Portas, M. (2007). The relationship between preseason range of motion and 334 muscle strain injury in elite soccer players. Journal of Strength and Conditioning Research, 335 21(4), 1155-1159.

336 Carling, C., \& Orhant, E. (2010). Variation in body composition in professional soccer players: 337 interseasonal and intraseasonal changes and the effects of exposure time and player position. The 338 Journal of Strength \& Conditioning Research, 24(5), 1332-1339.

339 Cejudo, A., Ayala, F., Sainz de Baranda, P., \& Santonja F. (2015b). Reliability of two methods

340 of clinical examination of the flexibility of the hip adductor muscles. The International Journal

341 of Sports Physical Therapy, 10(7), 976-983.

342 Cejudo, A., Sainz de Baranda, P., Ayala, F., \& Santonja, F. (2014a). Perfil de flexibilidad de la 343 extremidad inferior en jugadores de fútbol sala. Revista Internacional de Medicina y Ciencias de 344 la Actividad Física y el Deporte, 14(55), 509-525.

345 Cejudo, A., Sainz de Baranda, P., Ayala, F., \& Santonja, F. (2014b). A simplified version of the 346 weightbearing ankle lunge test: Description and test-retest reliability. Manual Therapy, 36(2), 347 278-285.

348 Cejudo, A., Sainz de Baranda, P., Ayala, F., \& Santonja, F. (2015a). Test-retest reliability of

349 seven common clinical tests for assessing lower extremity muscle flexibility in futsal and 350 handball players. Physical Therapy in Sport, 16(2), 107-113. 
351 Cohen, J. W. (1988). Statistical power analysis for the behavioral sciences. Hillsdale, NJ:

352 Lawrence Erlbaum Associates.

353 Delgado, O., Martín, M.A., Zurita, F., Antequera, J.J., \& Fernández, M. (2009). Evolutividad de

354 la capacidad flexora según el sexo y el nivel de enseñanza. Apunts Medicina de

355 l'Esport, 44(161), 10-17.

356 De Ste Croix, M., \& Korff, T. (2013). Paediatric biomechanics and motor control: theory and

357 application. London: Routledge.

358 Di Salvo, V., Baron, R., Tschan, H., Calderon Montero, F.J., Bachl, N., \& Pigozzi, F. (2007).

359 Performance characteristics according to playing position in elite soccer. International Journal of

360 Sports Medicine, 28(3), 222-7.

361 DiStefano, L. J., Padua, D. A., DiStefano, M. J., \& Marshall, S. W. (2009). Influence of age, sex,

362 technique, and exercise program on movement patterns after an anterior cruciate ligament injury

363 prevention program in youth soccer players. The American Journal of Sports Medicine, 37(3),

364 495-505. http://doi.org/10.1177/0363546508327542

365 Dvorak, J., Junge, A., \& Graf-Baumann, T. (2004). Football is the most popular sport worldwide.

366 The American Journal of Sports Medicine, 32, S3-4.

367 Feldman, D., Shrier, I., Rossignol, M., \& Abenhaim, L. (1999). Adolescent growth is not

368 associated with changes in flexibility. Clinical Journal of Sport Medicine, 9(1), 24-29.

369 FIFA (2006). FIFA big count 2006: 270 million people active in football. Retrieved from

370 www.fifa.com/aboutfifa/media/newsid=529882.html.

371 García-Pinillos, F., Ruiz-Ariza, A., Moreno del Castillo, R., \& Latorre-Román, P.Á. (2015).

372 Impact of limited hamstring flexibility on vertical jump, kicking speed, sprint, and agility in

373 young football players. Journal of Sports Sciences, 33(12), 1293-1297

374 http://dx.doi.org/10.1080/02640414.2015.1022577

375 Gerhardt, J., Cocchiarella, L., \& Lea, R. (2002). The Practical Guide to Range of Motion

376 Assessment. Chicago: American Medical Association.

377 Gómez-Landero, L.A.; Vernetta, M.; López-Bedoya, J. (2013). Perfil motor del trampolín

378 gimnástico. Revisión taxonómica y nuevas propuestas de clasificación. Revista Internacional de

379 Ciencias del Deporte, 30(9), 60-78.

380 Haugen, T. A., Tonnessen, E., \& Seiler, S. (2013). Anaerobic performance testing of

381 professional soccer players 1995-2010. International Journal of Sports Physiology and

382 Performance, 8, 148-156.

383 Henderson, G., Barnes, C. A., \& Portas M., D. (2010). Factors associated with increased

384 propensity for hamstring injury in English Premier League soccer players. Journal of Science

385 and Medicine in Sport, 13, 397-402.

386 Johns, R. J., \& Wright, V. (1962). Relative importance of various tissues in joint stiffness.

387 Journal of Applied Physiology, 17(5), 824-828.

388 Kellis, E., \& Katis, A. (2007). Biomechanical characteristics and determinants of instep soccer

389 kick. Journal of Sports Science \& Medicine, 6(2), 154. 
390 Kiani, A., Hellquist, E., Ahlqvist, K., Gedeborg, R., Michaëlsson, K., \& Byberg, L. (2010). 391 Prevention of soccer-related knee injuries in teenaged girls. Archives of Internal Medicine,

392 170(1), 43-49. http://doi.org/10.1001/archinternmed.2009.289

393 Kraemer, W. J. \& Gómez, A. L. (2001). Establisihing a Solid Fitness Base. In B. Foran (ed).

394 High-Performance Sports Conditioning, (pp.3-17). Champaign, IL: Human Kinetics.

395 Krustrup, P., Aagaard, P., Nybo, L., Petersen, J., Mohr, M., Bangsbo, J. (2010). Recreational

396 football as a health promoting activity: a topical review. Scandinavian Journal of Medicine \&

397 Science in Sports, 20(s1), 1-13.

398 Le Gall, F., Carling, C., Williams, M., \& Reilly, T (2010). Anthropometric and Fitness

399 characteristics of international, professional and amateur male graduate soccer player from elite 400 youth academy. Journal of Science and Medicine in Sport, 13(1), 90-95.

401 Lloyd, R. S., \& Oliver, J. L. (2012). The youth physical development model: A new approach to 402 long-term athletic development. The Strength \& Conditioning Journal, 34(3), 61-72.

403 López-Valenciano, A., Ayala, F., Vera-García, F. J., De Ste, C. M., Hernández-Sánchez, S.,

404 Ruiz-Pérez, I., ... \& Santonja, F. (2017). Comprehensive profile of hip, knee and ankle ranges of 405 motion in professional football players. The Journal of Sports Medicine and Physical Fitness.

406 Magee, D.J. (2002). Orthopedic physical assessment, (4th ed.), vol. 11. W.B. Saunders

407 Company: Philadelphia, Pennsylvania.

408 Malina, R. M., Ribeiro, B., Aroso, J., \& Cumming, S. P. (2007). Characteristics of youth soccer 409 players aged 13-15 years classified by skill level. British Journal of Sports Medicine, 41(5), 290410 295. doi: $10.1136 /$ bjsm.2006.031294

411 Manning, C., \& Hudson, Z.. (2009). Comparison of hip joint range of motion in professional

412 youth and senior team footballers with age-matched controls: an indication of early degenerative 413 change? Physical Therapy in Sport, 10(1), 25-9. https://doi.org/10.1016/j.ptsp.2008.11.005

414 McKay, M. J., Baldwin, J. N., Ferreira, P., Simic, M., Vanicek, N., Burns, J., ... \& Sman, A. 415 (2017). Normative reference values for strength and flexibility of 1,000 children and adults. 416 Neurology, 88(1), 36-43.

417 Medeiros, H. B. O., Araújo, D. S. M. S., \& Araújo, C. G. S. (2013). Age-related mobility loss is 418 joint-specific: an analysis from 6,000 Flexitest results. Age, 35(6), 2399-2407.

419 https://doi.org/10.1007/s11357-013-9525-Z

420 Milanese, C., Cavedon, V., Corradini, G., De Vita, F., \& Zancanaro, C. (2015). Seasonal DXA-

421 measured body composition changes in professional male soccer players. Journal of Sports

422 Sciences, 33(12), 1219-1228.

423 Mills, M., Frank, B., Goto, S., Blackburn, T., Cates, S., Clark, M., Aguilar, A., Fava N., \& Padua 424 D. (2015). Effect of restricted hip flexor muscle length on hip extensor muscle activity and lower 425 extremity biomechanics in college-aged female soccer players. International Journal of Sports 426 Physical Therapy, 10(7), 946-54.

427 Nikolaïdis, P.T. (2012). Age-Related Differences of Hamstring Flexibility in Male Soccer 428 Players, Baltic Journal of Health and Physical Activity, 4(2), 110-115. doi:10.2478/v10131-012429 0012-1. 
430 Nikolaidis, P., Ziv, G., Lidor, R., \& Arnon, M. (2014). Inter-individual variability in soccer 431 players of different age groups playing different positions. Journal of Human Kinetics, 40(1), 432 213-225.

433 Nogueira, M., Laiginhas, R., Ramos, J., \& Costa, O. (2017). Injuries in Portuguese amateur 434 youth football players: A six month prospective descriptive study. Acta Médica Portuguesa, $43530(12), 840-847$.

436 Nunome, H., Ikegami, Y., Kozakai, R., Apriantono, T., \& Sano, S. (2006). Segmental dynamics 437 of soccer instep kicking with the preferred and non-preferred leg. Journal of Sports Science, 24, 438 529-541.

439 Oberg, B., Ekstrand, J., Möller, M., \& Gillquist, J. (1984). Muscle strength and flexibility in 440 different positions of soccer players. International Journal of Sports Medicine, 5(4), 213-216.

441 Ostojić, S. M., \& Stojanović, M. D. (2007). Range of motion in the lower extremity elite vs non442 elite soccer players. Serbian Journal of Sports Sciences, 1(2), 74-78.

443 Oyón, P., Franco, L., Rubio, F. J., \& Valero, A. (2016). Young women soccer players.

444 Anthropometric and physiological characteristics. Evolution in a sports season. Archivos de 445 Medicina del Deporte, 33(1), 24-28

446 Palmer, M. L., \& Epler, M. E. (2002). Fundamentos de las técnicas de la evaluación 447 musculoesquelética. Barcelona: Paidotribo.

448 Pion, J., Segers, V., Fransen, J., Debuyck, G., Deprez, D., Haerens, L., ... \& Lenoir, M. (2015).

449 Generic anthropometric and performance characteristics among elite adolescent boys in nine 450 different sports. European Journal of Sport Science, 15(5), 357-366.

451 Piqueras-Rodríguez, F., Palazón-Bru, A., \& Gil-Guillén, V. F. (2016). Effectiveness Analysis of 452 active stretching versus active stretching plus low-frequency electrical stimulation in children 453 who play soccer and who have the short hamstring syndrome. Clinical Journal of Sport 454 Medicine, 26(1), 59-68.

455 Piqueras-Rodríguez, F., Palazón-Bru, A., Martínez-St John, D. R. J., Folgado-de la Rosa, D. M., 456 \& Gil-Guillén, V. F. (2016). A tool to quickly detect short hamstring syndrome in boys who play 457 soccer. International Journal of Sports Medicine, 37(01), 1-5.

458 Price, R. J., Hawkins, R. D., Hulse, M. A., \& Hodson, A. (2004). The Football Association 459 medical research programme: an audit of injuries in academy youth football. British Journal of 460 Sports Medicine, 38(4), 466-471. http://doi.org/10.1136/bjsm.2003.005165

461 Rahnama, N., Lees, A., \& Bambaecichi, E. (2005). Comparison of muscle strength and 462 flexibility between the preferred and non-preferred leg in English soccer players. Ergonomics, 463 48(11-14), 1568-1575.

464 Rebelo, A., Brito, J., Seabra, A., Oliveira, J., \& Krustrup, P. (2014). Physical match performance 465 of youth football players in relation to physical capacity. European Journal of Sport Science, 466 14(sup1), S148-S156.

467 Rubini, E. C., Costa, A., \& Gomes, P. (2007). The effects of stretching on strength performance. 468 Sports Medicine, 37(3), 213-24. 
469 Sainz de Baranda, P., \& Ayala, F. (2010). Chronic Flexibility improvement after 12 week of 470 stretching program utilizing the ACSM recommendations: Hamstring Flexibility. International 471 Journal of Sports Medicine, 31(6), 389-396.

472 Sainz de Baranda, P., Cejudo, A., Ayala, F., \& Santonja, F. (2015). Perfil óptimo de flexibilidad 473 del miembro inferior en jugadoras de fútbol sala. Revista Internacional de Medicina y Ciencias 474 de la Actividad Física y del Deporte, 15(60), 647-662.

475 Sainz de Baranda, P., Rodríguez-Iniesta, M., Ayala, F., Santonja, F., \& Cejudo, A. (2014).

476 Determination of the criterion-related validity of hip joint angle test for estimating hamstring 477 flexibility using a contemporary statistical approach. Clinical Journal of Sport Medicine, 24(4), 478 320-325.

479 Santonja, F., Ferrer, V. \& Martínez, I. (1995). Exploración clínica del síndrome de isquiosurales 480 cortos. Selección, 4(2), 81-91.

481 Stolen, T., Chamari, K., Castagna, C., \& Wisloff, U. (2005). Physiology of soccer. An update. 482 Sports Medicine, 35, 501-536.

483 Taylor, K. L., Sheppard, J. M., Lee, H., \& Plummer, N. (2009). Negative effect of static 484 stretching restored when combined with a sport specific warm-up component. Journal of Science 485 and Medicine in Sport, 12(6), 657-661.

486 Vaeyens, R., Malina, R. M., Janssen, M., Van Renterghem, B., Bourgois, J., Vrijens, J., \& 487 Philippaerts, R. M. (2006). A multidisciplinary selection model for youth soccer: the Ghent 488 Youth Soccer Project. British Journal of Sports Medicine, 40, 928-934. doi:

489 10.1136/bjsm.2006.029652

490 Witvrouw, E., Danneels, L., Asselman, P., D’Have, T., \& Cambier, D. (2003). Muscle Flexibility 491 as a Risk Factor for Developing Muscle Injuries in Male Professional Soccer Players. The 492 American Journal of Sports Medicine, 31(1), 41-46.

493 Wong, D. P., Hjelde, G. H., Cheng, C. F., \& Ngo, J. K. (2015). Use of the RSA/RCOD index to 494 identify training priority in soccer players. The Journal of Strength and Conditioning Research, 495 29, 2787-2793.

496 Wong, P. L. Chamari, K., Dellal, A., \& Wisloff, U (2009). Relationship between anthropometric 497 and physiological characteristics in youth soccer players. The Journal of Strength and 498 Conditioning Research, 23(4), 1204 -1210. 
499 Table 1. Demographic variables of the players of a soccer club (mean \pm standard deviation).

500 Table 2. Outfield based players' descriptive values (mean \pm SD) for 11 passive ranges of motion 501 in the five categories analyzed $(n=72)$.

502 Figure 1. Lower extremity ranges of motion of the "ROM-SPORT" protocol. (A) Hip flexion

503 with knee flexed test [HF-KF]; (B) hip flexion with knee extended test [HF-KE]; (C) Hip

504 extension test [HE]; (D) hip adduction with hip flexed $90^{\circ}$ test [HAD-HF90 ${ }^{\circ}$; (E) hip abduction

505 with hip neutral test [HAB]; (F) hip abduction with hip flexed $90^{\circ}$ test [HAB-HF90 ${ }^{\circ}$; (G) hip

506 internal rotation test [HIR]; $(\mathrm{H})$ hip external rotation test [HER]; (I) knee flexion test [KF]; (J)

507 ankle dorsiflexion with knee extended test [ADF-KE]; (K) ankle dorsiflexion with knee flexed

508 test [ADF-KF].

509 Figure 2. Age-related demands in flexibility in soccer players 8-19 years old. Statistically

510 significant differences between age group $(p \leq .040)$ with U10, U12, U14, U16, U19. (A) HAB:

511 hip abduction with hip neutral test; (B) HAB-HF90': hip adduction with hip flexed $90^{\circ}$ test; (C)

512 HER: hip external rotation test; (D) HIR: hip internal rotation test; (E) HAD-HF90': hip

513 adduction with hip flexed $90^{\circ}$ test. 


\section{Table $\mathbf{1}$ (on next page)}

Demographic variables of the players of a soccer club (mean \pm standard deviation).

BMI: body mass index 
Table 1. Demographic variables of the players of a soccer club (mean \pm standard deviation).

\begin{tabular}{lcccccc}
\hline & $\begin{array}{c}\mathrm{U10} \\
(\mathrm{n}=16)\end{array}$ & $\begin{array}{c}\mathrm{U12} \\
(\mathrm{n}=15)\end{array}$ & $\begin{array}{c}\mathrm{U14} \\
(\mathrm{n}=13)\end{array}$ & $\begin{array}{c}\mathrm{U16} \\
(\mathrm{n}=15)\end{array}$ & $\begin{array}{c}\mathrm{U} 19 \\
(\mathrm{n}=13)\end{array}$ & $\begin{array}{c}\text { Total } \\
(\mathrm{n}=72)\end{array}$ \\
\hline Age (years) & $8.9 \pm 0.9$ & $11.6 \pm 0.5$ & $12.7 \pm .7$ & $14.9 \pm 0.7$ & $17.7 \pm .8$ & $13.0 \pm 3.1$ \\
Body mass $(\mathrm{kg})$ & $33.5 \pm 6.3$ & $39.7 \pm 6.4$ & $52.1 \pm 8.8$ & $62.0 \pm 9.1$ & $70.2 \pm 5.2$ & $50.5 \pm 15.3$ \\
Height $(\mathrm{cm})$ & $136.4 \pm 6.7$ & $149.3 \pm 8.3$ & $161.0 \pm 8.7$ & $172.2 \pm 7.7$ & $176.9 \pm 5.5$ & $158.2 \pm 16.8$ \\
BMI $\left(\mathrm{kg} / \mathrm{m}^{2}\right)$ & $17.9 \pm 2.21$ & $17.6 \pm 1.1$ & $19.7 \pm 2.3$ & $20.5 \pm 1.8$ & $22.6 \pm 1.8$ & $19.6 \pm 2.6$ \\
\hline
\end{tabular}

BMI: body mass index

1 


\section{Table 2 (on next page)}

Outfield based players' descriptive values (mean \pm SD) for 11 passive ranges of motion in the five categories analyzed $(n=72)$.

aSignificantly different from U10 ( $p<.05)$; ${ }^{b}$ Significantly different from U12 $(p<.05)$;

'Significantly different from U14 ( $p<.05)$; ${ }^{d}$ Significantly different from U16 $(p<.05)$;

eSignificantly different from U19 ( $p<.05$ ); HE: hip extension test; HAD-HF90: hip adduction with hip flexed $90^{\circ}$ extended test; ADF-KE: ankle dorsiflexion with knee extended test; ADFKF: ankle dorsiflexion with knee flexed test; HAB: hip abduction test; HIR: hip internal rotation test; HER: hip external rotation test; HAB-HF90: hip abduction with hip flexed $90 \circ$ test; HFKE: hip flexion with knee extended test; KF: knee flexion test; HF-KF: hip flexion with knee flexed test. 
Table 2. Outfield based players' descriptive values (mean $\pm \mathrm{SD}$ ) for 11 passive ranges of motion in the five categories analyzed $(n=72)$.

\begin{tabular}{|c|c|c|c|c|c|c|}
\hline $\begin{array}{l}\text { Range of motion } \\
\text { (grades) }\end{array}$ & $\begin{array}{c}\text { U10 } \\
(\mathrm{n}=16)\end{array}$ & $\begin{array}{c}\text { U12 } \\
(\mathrm{n}=15)\end{array}$ & $\begin{array}{c}\text { U14 } \\
(\mathrm{n}=13)\end{array}$ & $\begin{array}{c}\text { U16 } \\
(n=15)\end{array}$ & $\begin{array}{c}\text { U19 } \\
(\mathrm{n}=13)\end{array}$ & $\begin{array}{c}\text { Total } \\
(\mathrm{n}=72)\end{array}$ \\
\hline $\mathrm{HE}$ & $16.8^{\circ} \pm 8.1^{\circ}$ & $17.7^{\circ} \pm 6.2^{\circ}$ & $12.4^{\circ} \pm 4.9^{\circ}$ & $12.3^{\circ} \pm 8.1^{\circ}$ & $11.4^{\circ} \pm 6.0^{\circ}$ & $14.3^{\circ} \pm 7.2^{\circ}$ \\
\hline${\mathrm{HAD}-\mathrm{HF} 90^{\circ}}^{\circ}$ & $39.6^{\circ} \pm 4.3^{\circ} d$ & $38.1^{\circ} \pm 4.1^{\circ}$ & $38.4^{\circ} \pm 3.2^{\circ}$ & $34.9^{\circ} \pm 5.4^{\circ} a$ & $36.2^{\circ} \pm 4.8^{\circ}$ & $37.5^{\circ} \pm 4.6^{\circ}$ \\
\hline ADF-KE & $32.3^{\circ} \pm 4.1^{\circ}$ & $29.7^{\circ} \pm 3.8^{\circ}$ & $31.3^{\circ} \pm 3.3^{\circ}$ & $31.6^{\circ} \pm 5.1^{\circ}$ & $30.6^{\circ} \pm 3.9^{\circ}$ & $31.1^{\circ} \pm 4.1^{\circ}$ \\
\hline ADF-KF & $36.4^{\circ} \pm 4.0^{\circ}$ & $34.8^{\circ} \pm 4.1$ & $36.5^{\circ} \pm 4.6^{\circ}$ & $35.8^{\circ} \pm 4.8^{\circ}$ & $34.6^{\circ} \pm 4.2^{\circ}$ & $35.6^{\circ} \pm 4.3^{\circ}$ \\
\hline HAB & $34.5^{\circ} \pm 3.7^{\circ} c$ & $35.6^{\circ} \pm 3.0^{c, d}$ & $29.6^{\circ} \pm 4.9^{\circ} a, b, e$ & $31.5^{\circ} \pm 4.5^{\circ} b$ & $34.4^{\circ} \pm 2.9^{\circ} c$ & $33.2^{\circ} \pm 4.4^{\circ}$ \\
\hline HIR & $55.7^{\circ} \pm 8.5^{\circ}$ & $60.8^{\circ} \pm 4.7^{\circ} d, e$ & $55.4^{\circ} \pm 7.7^{\circ}$ & $49.5^{\circ} \pm 8.1^{\circ} b$ & $49.6^{\circ} \pm 8.4^{\circ} b$ & $54.3^{\circ} \pm 8.5^{\circ}$ \\
\hline HER & $63.5^{\circ} \pm 5.6^{\circ} b, e$ & $50.1^{\circ} \pm 4.8^{\circ} a, d$ & $55.7^{\circ} \pm 12.7^{\circ}$ & $61.2^{\circ} \pm 5.6^{\circ} b, e$ & $50.4^{\circ} \pm 11.1^{\circ} a, d$ & $56.4^{\circ} \pm 9.8^{\circ}$ \\
\hline $\mathrm{HAB}^{2} \mathrm{HF} 90^{\circ}$ & $64.1^{\circ} \pm 7.5^{\circ} c, d, e$ & $62.8^{\circ} \pm 4.8^{\circ} c, d, e$ & $55.3^{\circ} \pm 5.4^{\circ} a, b$ & $53.9^{\circ} \pm 6.1^{\circ} a, b$ & $53.3^{\circ} \pm 6.8^{\circ} a, b$ & $58.1^{\circ} \pm 7.6^{\circ}$ \\
\hline HF-KE & $70.0^{\circ} \pm 9.8^{\circ}$ & $69.7^{\circ} \pm 7.8^{\circ}$ & $70.3^{\circ} \pm 8.5^{\circ}$ & $73.4^{\circ} \pm 9.9^{\circ}$ & $74.4^{\circ} \pm 8.2^{\circ}$ & $71.5^{\circ} \pm 8.9^{\circ}$ \\
\hline $\mathrm{KF}$ & $130.8^{\circ} \pm 15.1^{\circ}$ & $133.8^{\circ} \pm 7.1^{\circ}$ & $127.0^{\circ} \pm 9.1^{\circ}$ & $124.8^{\circ} \pm 10.6^{\circ}$ & $120.4^{\circ} \pm 16.4^{\circ}$ & $127.6^{\circ} \pm 12.7^{\circ}$ \\
\hline HF-KF & $136.8^{\circ} \pm 9.1^{\circ}$ & $135.2^{\circ} \pm 5.6^{\circ}$ & $136.3^{\circ} \pm 3.7^{\circ}$ & $131.4^{\circ} \pm 6.8^{\circ}$ & $136.9^{\circ} \pm 7.3^{\circ}$ & $135.3^{\circ} \pm 7.0^{\circ}$ \\
\hline
\end{tabular}

${ }^{a}$ Significantly different from U10 (p $\left.<.05\right) ;{ }^{b}$ Significantly different from U12 $(\mathrm{p}<.05) ;{ }^{c}$ Significantly different from U14 (p $\left.<.05\right) ;{ }^{d}$ Significantly different from U16 $(\mathrm{p}<.05)$; ${ }^{e}$ Significantly different from U19 $(\mathrm{p}<.05)$; HE: hip extension test; HAD-HF90 $0^{\circ}$ : hip adduction with hip flexed $90^{\circ}$ extended test; ADF-KE: ankle dorsiflexion with knee extended test; ADF-KF: ankle dorsiflexion with knee flexed test; HAB: hip abduction test; HIR: hip internal rotation test; HER: hip external rotation test; HAB-HF90 ${ }^{\circ}$ : hip abduction with hip flexed $90^{\circ}$ test; HF-KE: hip flexion with knee extended test; KF: knee flexion test; HF-KF: hip flexion with knee flexed test. 


\section{Figure 1}

Lower extremity ranges of motion of the "ROM-SPORT" protocol.

(A) Hip extension test [HE]; (B) hip adduction with hip flexed 900 test [HAD-HF90]; (C) hip flexion with knee flexed test [HF-KF]; (D) hip flexion with knee extended test [HF-KE]; (E) hip abduction with hip neutral test [HAB]; (F) hip abduction with hip flexed 90 test [HAB-HF900]; (G) hip external rotation test [HER], (H) hip internal rotation test [HIR]; (I) knee flexion test [KF]; (J) ankle dorsiflexion with knee flexed test [ADF-KF]; (K) ankle dorsiflexion with knee extended test [ADF-KE].

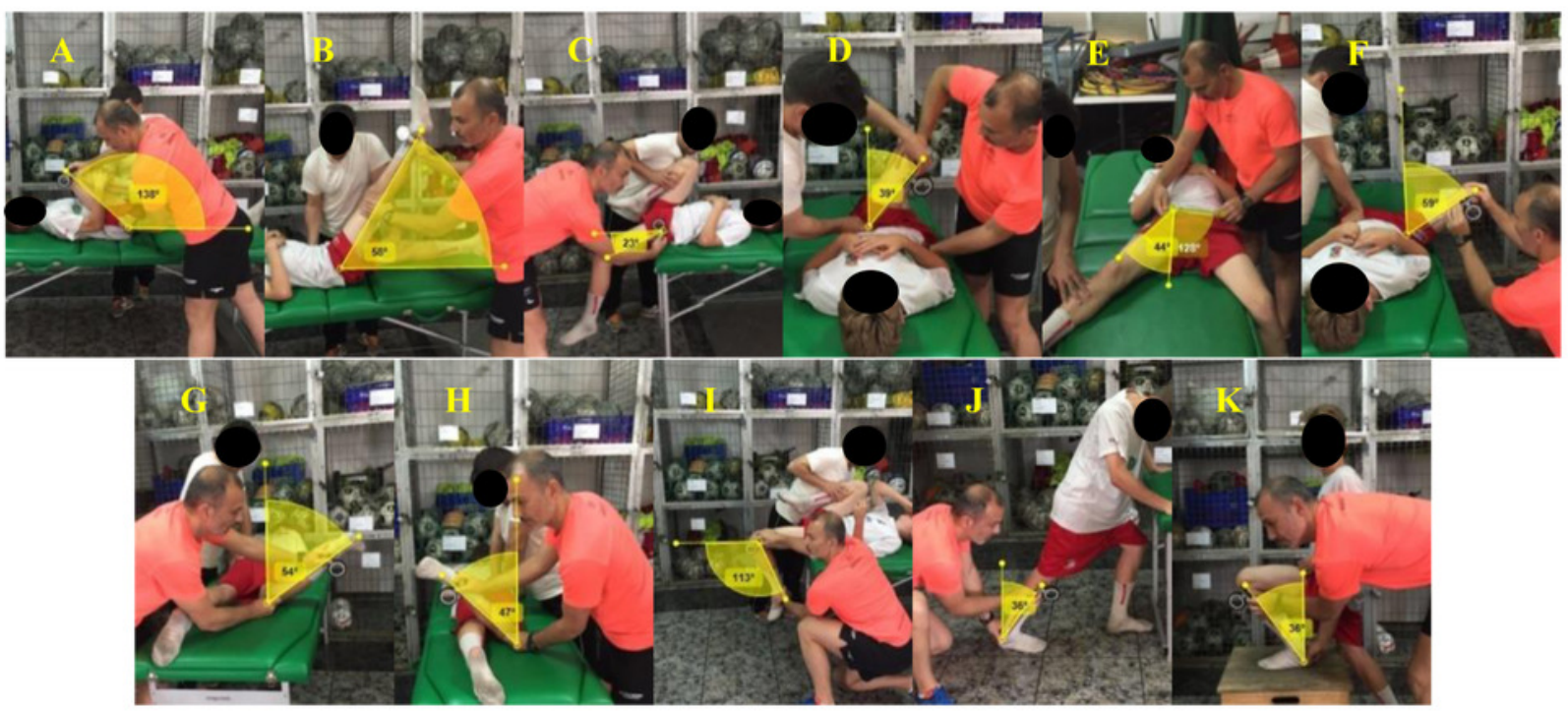


Figure 2

Age-related demands in flexibility in soccer players 8-19 years old. Statistically significant differences between age group ( $p \leq .040)$ with U10, U12, U14, U16, U19.

(A) HAB: hip abduction with hip neutral test; (B) HAB-HF90: hip adduction with hip flexed 90ㅇ test; (C) HER: hip external rotation test; (D) HIR: hip internal rotation test; (E) HAD-HF90: hip adduction with hip flexed $90^{\circ}$ test.
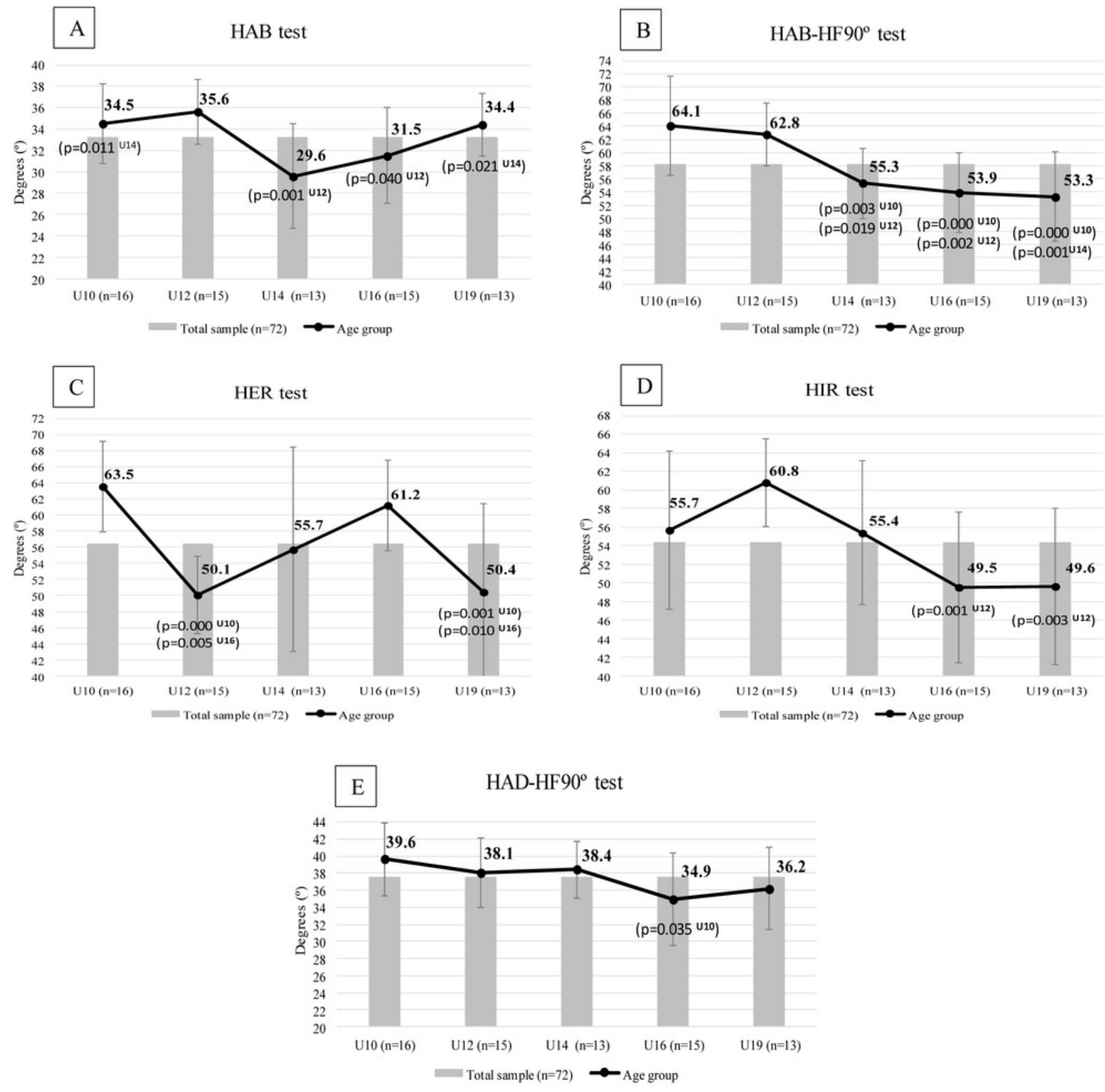